\title{
MANAJEMEN PIMPINAN LEMBAGA KURSUS DALAM PEMBINAAN KUALITAS PENDIDIK TATA RIAS PENGANTIN
}

\author{
Deti Rostini \\ Dosen Universitas Islam Nusantara \\ Email: deti.rostini@uninus.ac.id
}

\begin{abstract}
Abstrak
Permasalahan di dunia pendidikan non formal dan pengajaran pada umumnya sering terjadi pada pendidik tata rias pengantin antara lain 1) lemahnya peran serta pendidik tata rias pengantin dalam melaksanakan tugasnya masih menganggap hal yang rutinitas tanpa perubahan, baik dalam strategi, metode, teknik, media, dan lain-lain, serta 2) permasalahan tentang peran pimpinan lembaga kursus sebagai motivator dan manajer dalam pengelolaan sumber daya manusia yang tidak berjalan sebagai mana mestinya. Jalan keluar untuk mengatasi hal ini antara lain dapat dilakukan oleh pimpinan lembaga kursus sebagai pemimpin tertinggi menerapkan sistem pembinaan terhadap pendidik tata rias pengantin agar berkualitas dan dapat ditingkatkan. Manajemen pembinaan pendidik tata rias pengantin merupakan langkah yang tepat dalam mengatasi permasalahan diatas. Langkah-langkah yang dapat dilakukan adalah pimpinan lembaga kursus dan jajarannya membuat perencanaan pembinaan, pengorganisasian, pelaksanaan pembinaan, dan evaluasi hasil dari pembinaan. Dengan langkah ini akan diketahui hasil dan kemajuan dari kinerja pendidik tata rias pengantin dan tujuan dari pendidikan tata rias pengantin itu sendiri. Teori yang dipakai dalam menunjang penelitian dan pembinaan profesionalitas pemimpin kursus antara lain adalah teori tentang manajemen pendidikan, manajemen pimpinan lembaga kursus, serta teori tentang pembinaan. Teknik penelitian menggunakan studi dokumentasi, wawancara dan observasi, dengan metode dan pendekatan kualitatif deskriptif. Subjek dalam penelitian adalah pimpinan dan pendidik tata rias pengantin di lembaga kursus. Berdasarkan hasil temuan penelitian dapat disimpulkan bahwa di lembaga kursus selalu secara rutin melaksanakan 1) perencanaan pembinaan pada setiap tahunnya; 2) pengorganisasian sesuai dengan tugas pokok dan fungsi; 3) pelaksanaan pembinaan secara rutin; dan 4) melakukan evaluasi terhadap hasil dari pembinaan.
\end{abstract}

Kata kunci : Manajemen Pimpinan Kursus; Pembinaan; Pendidik Perias Pengantin

\begin{abstract}
Problems in the world of non-formal education and teaching in general often occur in bride cosmetology educators, among others 1) the weak participation of bride cosmetology educators in carrying out their duties still considers routines without change, both in strategy, methods, techniques, media, and etc., and 2) issues regarding the role of the course leader as a motivator and manager in the management of human resources that are not working properly. The way out to overcome this can be done among others by the leadership of the course institution as the supreme leader to implement a system of guidance for bride cosmetology educators to be quality and can be improved. The management of bride cosmetology educators is the right step in overcoming the above problems. The steps that can be taken are the leadership of the course institutions and their staff to make coaching plans, organizing, implementing coaching, and evaluating the results of coaching. With this step we will know the results and progress of the bride cosmetology educator's performance and the goals of the bride cosmetology education itself. Theories used in supporting research and coaching professionalism of course leaders include theories about management education, management of course leaders, and theories about coaching. The research technique uses documentation studies, interviews and observations, with descriptive qualitative methods and approaches. The subjects in the study were the leaders and educators of bridal make-up in the course institutions. Based on the findings of the research it can be concluded that in the institute the course always routinely carries out 1) coaching planning every year; 2 ) organizing according to the main tasks and functions; 3 ) regular coaching implementation; and 4) evaluating the results of the coaching.
\end{abstract}

Keywords : Management of Course Leaders; Bride Makeup Artist Coaching; Educators 


\section{A. PENDAHULUAN}

Pendidik khususnya untuk kejuruan tata rias pengantin adalah garda terdepan dalam pendidikan non formal, merupakan pendidik profesional dengan beberapa tugas utama mendidik, mengajar, membimbing, mengarahkan, melatih, menilai, dan mengevaluasi. Tugas utama pendidik pada institusi pendidikan non formal yaitu di Lembaga kursus.

Tugas utama seorang pendidik tata rias pengantin akan menjadi efektif jika memiliki derajat profesionalitas yang tinggi yang tercermin dari empat kompetensi guru yang dimilikinya. Empat kompetensi yang harus dimiliki oleh seorang pendidik tata rias pengantin tersebut adalah kompetensi profesi, kompetensi sosial, kompetensi kepribadian, dan kompetensi pedagogik.

Kompetensi profesi dapat dimaknai sebagai keterampilan pendidik dalam menyampaikan materi tata rias pengantin kepada peserta didik yang dihadapinya. terlihat jika dapat menciptakan pembelajaran yang efektif, efisien, menyenangkan. Ditunjang dengan metode yang relevan dengan materi tata rias pengantin, serta penyampaian pembelajaran yang tidak membosankan. Pendidik profesional yang terpenting dapat memotivasi peserta didik untuk bergairah dalam belajar. Hal ini menjadi penting karena kompetensi profesi erat kaitannya dengan perencanaan dan pelaksanaan pembelajaran dalam kegiatan belajar mengajar.

\footnotetext{
Menurut UU Sisdiknas No.20 tahun 2003 Pendidik merupakan tenaga profesional yang bertugas merencanakan dan melaksanakan proses pembelajaran, menilai hasil pembelajaran, melakukan bimbingan dan pelatihan, serta melakukan penelitian dan pengabdian kepada masyarakat.
}

Secara formal guru profesional disyaratkan memenuhi kualifikasi akademik minimum Strata satu (S1) dan bersertifikat pendidik. Menurut UU Sisdiknas No.20 tahun 2003 pendidik harus memiliki kualifikasi minimum dan sertifikasi sesuai dengan jenjang kewenangan mengajar.

Pendidik profesional diharapkan dapat menghasilkan peserta didik yang berkualitas, sehingga pada akhirnya menghasilkan pendidikan yang berkualitas. Pendidikan berkualitas dalam suatu lingkungan lembaga kursus dipengaruhi oleh banyak faktor pendukung yang terdapat di lembaganya masing-masing.

Kualitas pendidikan dalam suatu lembaga kursus ditentukan oleh tiga variabel yakni: 1) kultur lembaga kursus; 2) proses belajar mengajar; dan 3) realitas lembaga kursus, kultur lembaga kursus adalah nilai-nilai, kebiasaan, sloganslogan, dan berbagai perilaku yang telah lama terbentuk di lembaga kursus. Kultur lembaga kursus dipengaruhi oleh seluruh warga lembaga kursus yakni Kepala sekolah, guru, staff, siswa, bahkan orang tua siswa. Sementara itu, proses belajar belajar mengajar dan realitas lembaga kursus merupakan komponen input lembaga kursus. Komponen input yang berkualitas akan membentuk sistem pendidikan yang berkualitas. Menurut Sukmadinata dalam Http://www.sambasalim.com komponen input diklasifikasikan menjadi tiga yaitu: 1) raw infut yakni peserta didik; 2) instrumental input yakni kebijakan, kurikulum, sarana, fasilitas, media, dan biaya; dan 3) environment input yakni lingkungan sekolah, keluarga, dan masyarakat.

Terkait dengan masalah mutu lembaga kursus, pimpinan dalam ruang lingkup lembaga kursus adalah salah satu komponen yang paling berperan dalam meningkatkan kualitas pendidikan sumber 
daya manusia di suatu lembaga kursus, serta orang terdepan dalam pengembangan kurikulum.

Motivasi pendidik dalam bekerja akan timbul dari pengaruh pimpinan sebagai motivatornya. Sehingga pada akhirnya pendidik dapat melaksanakan kinerjanya sebaik mungkin. Pimpinan lembaga kursus yang profesional akan memberikan dampak positif dan perubahan yang cukup mendasar dalam pembaruan sistem pendidikan di lembaga kursus. Dampak tersebut dapat terlihat pada efektifitas pendidikan, kepemimpinan lembaga yang kuat, pengelolaan tenaga kependidikan yang efektif, budaya mutu, team work yang kompak, cerdas, dinamis, mandiri, partisipasi warga lembaga kursus dan masyarakat, transparansi manajemen, perbaikan berkelanjutan, responsif, dan akuntabilitas.

Pembinaan pendidik agar lebih berkualitas dan profesional, harus menjadi pemicu bagi pimpinan lembaga kursus untuk menjadikan visi menjadi aksi. Kunci agar pimpinan dan tenaga pendidik tetap bertahan dalam memahami kerjasama dalam manajemen pendidikan adalah dengan memahami posisi masing-masing sesuai dengan tupoksinya. Berdasarkan permasalahan diatas, maka ada ketertarikan untuk menganalisis tentang ;

1) Perencanaan Pimpinan Lembaga Kursus dalam pembinaan pendidik tata rias pengantin;

2) Pengorganisasian Pimpinan Lembaga Kursus dalam pembinaan pendidik tata rias pengantin;

3) Pelaksanaan Pimpinan Lembaga Kursus dalam pembinaan pendidik tata rias pengantin; dan

4) Evaluasi Pimpinan Lembaga Kursus dalam pembinaan pendidik tata rias pengantin

\section{B. KAJIAN LITERATUR}

1) UU Sisdiknas No.20 tahun 2003 Pendidik merupakan tenaga profesional yang bertugas merencanakan dan melaksanakan proses pembelajaran, menilai hasil pembelajaran, melakukan bimbingan dan pelatihan, serta melakukan penelitian dan pengabdian kepada masyarakat. Secara non formal pendidik disyaratkan memenuhi kualifikasi akademik minimum Strata satu (S1) dan bersertifikat pendidik. Menurut UU Sisdiknas No.20 tahun 2003 pendidik harus memiliki kualifikasi minimum dan sertifikasi sesuai dengan jenjang kewenangan mengajar.

2) Sukmadinata dalam Http://www.sambasalim.com komponen infut diklasifikasikan menjadi tiga yaitu: 1) raw infut yakni peserta didik; 2) instrumental input yakni kebijakan, kurikulum, sarana, fasilitas, media, dan biaya; dan 3) environment input yakni lingkungan sekolah, keluarga, dan masyarakat.

3) Arikunto (2006:22)" Agar penelitian dapat dilaksanakan dengan sebaik-baiknya, maka peneliti harus merumuskan masalahnya sehingga jelas dari mana harus memulai, kemana harus pergi, dan dengan apa".

4) George R.Terry (dalam Sarwoto, 1987:87) mendefinisikan pergerakan sebagai tindakan untuk mengusahakan agar semua anggota kelompok suka berusaha untuk mencapai sasaran-sasaran agar sesuai dengan perencanaan manajerial. 


\section{METODE PENELITIAN}

Pendekatan yang digunakan dalam penelitian adalah pendekatan kualitatif naturalistik. Sugiyono (2013;15) mengemukakan "Pendekatan penelitian kualitatif sering disebut dengan pendekatan naturalistik karena : a) penelitian dilakukan pada kondisi yang alamiah/natural setting; b) penelitian berlandaskan pada filsafat postpositivisme atau paradigma interpretatif konstruktif yang memandang realitas sosial sebagai sesuatu yang holistik, kompleks, dinamis, penuh makna; c) objek alamiah apa adanya; d) pengambilan sampel acak; e) teknik triangulasi (gabungan tiga instrumen penelitian); dan f) analisis induktif menekankan makna.

Metode yang dipakai dalam penelitian adalah deskriptif, menurut Nasution (2006: 63) "Penelitian deskriptif disebut kegiatan pengumpulan data untuk memberikan gambaran atau gagasan suatu konsep atau gejala, juga menjawab pertanyaan-pertanyaan sehubungan dengan status subjek penelitian pada saat ini"'

1. Teknik Pengumpulan Data

2. Teknik Analisis Data

3. Sumber Data

\section{HASIL DAN PEMBAHASAN}

\section{Tahap Penyusunan Perencanaan Pimpinan Lembaga Kursus Dalam Pembinan Pendidik Tata Rias Pengantin}

Perencanaan dapat disusun berdasarkan kebutuhan dalam jangka waktu tertentu sesuai dalam batas waktu tertentu. Pada pembaga kursus yang dijadikan penelitian penetapan visi dan misi, tujuan, dan strategi merupakan tahap perencanaan yang perlu ada dan didukung seluruh komponen lembaga kursus. Penetapan program yang berjangka waktu tertentu dibuat agar tujuan dari manajemen lembaga kursus dapat tercapai. Program pembinaan kinerja guru dibuat dengan tujuan antara lain : 1) pendidik rias pengantin harus berinovasi; 2) Pendidik rias pengantin harus memperhatikan kebutuhan peserta didik baik akademis maupun potensi keterampilan lainnya 3) Pendidik rias pengantin harus senantiasa menambah ilmu dan pengalaman; dan 4) Pendidik rias Pengantin harus berdaya saing yang positif dan kompetitif.

Pada tahap ini lembaga kursus terlebih dahulu menyusun perencanaan yang di dalamnya memuat antara lain : materi yang akan dilaksanakan dalam rangka pembinaan, menentukan sasaran tujuan yang ingin dicapai, menyusun program kerja tahunan, melaksanakan rapat bulanan, melaksanakan supervisi baik manajerial maupun akademis, melaksanakan workshop, mengikutsertakan pendidik tata rias dalam berbagai kegiatan. Seperti seminar, pelatihan metodelogi, dll.

\section{Tahap Pengorganisasian Pimpinan Lembaga Kursus Dalam Pembinaan Pendidik Tata Rias Pengantin}

Agar program peningkatan kinerja pendidik tata rias pengantin berjalan sesuai dengan apa yang direncanakan. Terlebih dahulu disusun struktur organisasinya sehingga apa, siapa, dan kapan program itu harus berjalan, struktur organisasi yang dibuat disesuaikan dengan situasi dan kondisi pada saat itu. Prosedur pembentukan struktur organisasi diperlukan agar tujuan dari apa yang direncanakan jelas tupoksinya. Tujuan tercapai dengan efektif dan efisien.

Seperti apa yang dikatakan Manullang (1981 : 12) "pengorganisasian adalah hubungan yang tepat antar personel dengan maksud agar semua yang terlibat dapat bekerja secara efisien dalam mencapai tujuan yang sudah ditentukan sebelumnya". 
Pembentukan struktur organisasi kegiatan peningkatan dan pembinaan kinerja pendidik tata rias pengantin oleh Pimpinan lembaga kursus ditentukan melalui rapat lembaga pimpinan lembaga kursus sebagai manajer bisa menunjuk siapa saja dengan jalan musyawarah dengan seluruh stakeholder di lembaga kursus tersebut. Sehingga seluruh tenaga yang, ada mempunyai kesempatan yang sama untuk terlibat dalam kegiatan peningkatan dan pembinaan kinerja pendidik tata rias pengantin tersebut. Susunan organisasi ini perlu mendapat dukungan dan kesepakatan agar masingmasing bekerja sesuai tugas pokok dan fungsinya.

Agar pengorganisasian berjalan dengan baik maka pimpinan kursus harus memilki strategi yang tepat untuk memberdayakan tenaga kependidikan melalui kerjasama yang kooferatif dan solid. Kerjasama pada semua lini baik vertikal maupun horizontal harus dilakukan pimpinan kursus jika ingin program berjalan efektif dan efisien.

Pada tahap ini kegiatan pembinaan kinerja guru dibentuk kepanitiaan yang terdiri dari stakeholder pada lembaga kursus antara lain : penanggung jawab yakni pimpinan lembaga kursus, ketua panitia penyelenggara dalam hal ini adalah wakil pimpinan, sekertaris, dan para pendidik senior.

\section{Tahap Pelaksanaan Pimpinan Lembaga Kursus Dalam Pembinaan Pendidik Tata Rias Pengantin}

Pembinaan kinerja pendidik tata rias pengantin dilakukan dengan : 1) pembinaan secara individu dan kelompok; 2) mengikut sertakan dalam kegiatan kegiatan di luar lembaga seperti pelatihan metodelogi, penataran, penyetaraan ijasah, workshop, seminar, pendampingan kurikulum, dll; 3) menambah sarana dan prasarana; 4) penilaian kinerja pendidik tata rias pengantin; dan 5) supervisi pendidik tata riasa pengantin.
Apa yang telah dilakukan oleh pimpinan lembaga kursus sesuai dengan apa yang dikemukakan oleh Mulyasa (2009 : 102) bahwa kemampuan mengembangkan tenaga kependidikan terutama berkaitan dengan pemberian kesempatan kepada tenaga kependidikan untuk mengikuti berbagai pendidikan dan pelatihan secara teratur melalui revitalisasi, kegiatan di HIPKI, diskusi, seminar, dan lokakarya.

Dalam konteks aplikatif kemampuan pendidik tata rias profesional dapat diwujudkan dalam penguasaan kompetensi berikut ini : 1) menguasai materi tentang tata rias pengantin; 2) dapat mengelola program belajar mengajar tata rias pengantin; 3) dapat mengelola kelas; 4) dapat menggunakan media dan sumber; 5) menguasai landasan pendidikan; 6) menguasai interaksi belajar mengajar tata rias pengantin; 7) menilai prestasi peserta didik; dan 8) mengenal administrasi lembaga kursus. Konteks aplikatif di atas dapat terwujud jika pimpinan lembaga kursus sebagai pemimpin dapat memberikan pembinaan dengan dengan tepat untuk pendidik tata rias yang menjadi rekan kerjanya. Kegiatan supervisi adalah merupakan kegiatan- kegiatan yang wajib dilaksanakan dalam penyelenggaraan pendidikan non formal. Pelaksanaan kegiatan supervisi dilaksanakan oleh pimpinan lembaga kursus dan pemilik lembaga kursus. Hal ini perlu dilakukan karena proses belajar mengajar tata rias pengantin yang dilaksanakan pendidik tata rias pengantin merupakan inti dari proses pendidikan secara keseluruhan sebagai pemegang peranan utama.

\section{Tahap Evaluasi Pimpinan Lembaga Kursus Dalam Pembinaan Pendidik Tata Rias}

Tujuan Pimpinan lembaga kursus dalam melaksanakan penilaian kinerja yang dilaksanakan pendidik tata rias pengantin dalam kurun satu semester. Bukan untuk mencari kesalahan yang dilakukan pendidik tata rias melainkan bertujuan untuk menilai 
kemampuan pendidik tata rias dalam menerapkan semua kompetensi keterampilan yang diperlukan dalam kegiatan belajar mengajar (KBM). Dengan demikian, kinerja pendidik tata rias pengantin sebagai gambaran kekuatan dan kelemahan pendidik tata rias akan teridentifikasi sebagai analisis kebutuhan atau keterampilan penilaian juga dimaksudkan untuk perencanaan pembinaan.

Penilaian pendidik tata rias pengantin dilaksanakan setiap semester yang meliputi; 1) kompetensi pedagogik; 2) kompetensi kepribadian; 3) kompetensi sosial; dan 4) kompetensi professional. Kegiatan evaluasi penilaian kinerja pendidik tata rias pengantin terdiri dari unsur yang dijadikan bahan evaluasi yakni sikap dan prilaku kerja, mengenal karakteristik peserta didik, menguasai teori belajar, menguasai prinsip belajar, bisa mengembangkan menjadi perias pengantin yang handal di masyarakat, kegiatan pembelajaran yang mendidik, memahami dan mengembangkan potensi, berkomunikasi dengan peserta didik, hasil belajar peserta didik. Pada tahap evaluasi pedoman lembaga kursus antara lain mengacu pada kurikulum kurikulum, kalender pendidikan, struktur organisasi sekolah, pembagian tugas mengajar, peraturan akademik, tata tertib lembaga kursus, dan biaya oprasional lembaga kursus.

\section{E. SIMPULAN}

DAN

\section{REKOMENDASI}

a. Kegiatan pimpinan lembaga kursus merencanakan pembinaan pendidik tata rias pengantin.

Dalam pembinaan pendidik tata rias pengantin dilakukan penyusunan yang diawali dengan analisis terhadap permasalahan yang dihadapi pendidik tata rias pengantin dalam pembelajaran, permasalahan diangkat dalam rapat kerja lembaga kursus. Permasalahan meliputi pengembangan perencanaan pembelajaran baik silabus maupun RPP, atau berupa pelaksanaan kegiatan belajar mengajar tata rias pengantin serta pemanfaatan teknologi informasi.

b. Kegiatan Pimpinan lembaga kursus mengorganisasikan pembinaan pendidik tata rias pengantin.

Kegiatan pengorganisasian terlebih dahulu diawali dengan mengadakan rapat pendidik tata rias pengantin untuk penyusunan koordinator atau kepanitiaan pelaksanaan pembinaan pendidik tata rias pengantin . Kepanitiaan tersebut menyangkut pimpinan lembaga kursus, wakil Pimpinan lembaga kursus, penanggung jawab, sekretaris, bendahara, dan anggota.

c. Kegiatan pimpinan lembaga kursus melaksanakan pembinaan pendidik tata rias pengantin.

Pelaksanaan pembinaan meliputi pelaksanaan Pendidik tata rias pengantin dan pelaksanaan pelatihan metodelogi, workshop, seminar, kesempatan melanjutkan studi baik yang belum $\mathrm{S} 1$, penataran, dan pelatihan HIPKI.

d. Kegiatan pimpinan kursus dalam evaluasi pembinaan pendidik tata rias pengantin

Kegiatan evaluasi pimpinan lembaga kursus melaksanakan evaluasi secara berkala berupa evaluasi perencanaan, evaluasi pelaksanaan, evaluasi penilaian, serta evaluasi tindak lanjut. Evaluasi bermanfaan bagi pimpinan kursus untuk mengukur ketercapaian dari tujuan yang telah ditetapkan, serta bahan untuk menyusun program kerja di tahun berikutnya.

\section{F. REFERENSI}

Ali, M. (1992). Strategi Penelitian Pendidikan. Bandung: Angkasa. 
Arifin, D dan Pipin Arifin. (2008). Teori EMASLIM. Bandung: Pustaaka Al Kasyaf.

Arifin, D dan Pipin Arifin. (2011). Keprofesionalan Seorang Guru. Bandung: Pustaka Al-Kasyaf

Arikunto, S. (2006). Manajemen Penelitian. Jakarta: Rineka Cipta

Bunyan. (2015). Peran Manajerial Kepala Sekolah Dalam Meningkatkan Kinerja Guru. Tesis S2 PPS Uninus.

Dadi,P dan Daeng Arifin. (2010). The Smiling Teacher. Bandung: Nuansa Aulia

Fredrick Taylor, W. Scientifick Management. (Happer and Breos). New York

Manullang, A. A. (2013). Manajemen Personalia. Medan: Ghalia Indonesia

Meleong. (2007). Metodologi Penelitian Kualitatif. Bandung: Rosdakarya.

Mulyasa, E. (2002). Manajemen Berbasis Sekolah. Bandung: Rosdakarya.

Mulyasa, E. (2013). Menjadi guru Profesional. Bandung: Rosdakarya.

Mulyasa, E. (2009). Menjadi Kepala Sekolah Profesional. Bandung: Rosdakarya.

Nasution. (2006). Kurikulum dan Pengajaran. Bandung: Bumi Aksara.

Permana dan Mulyana. 9225). Pengelolaan Kelas. UPI Bandung: Jurusan Adpen.

Sa'ud. (2008). Pengembangan Profesi Guru. Bandung: Alfabeta.

Sanusi, A. (2014). Pembaruan Strategi Pendidikan. Bandung : Nuansa Cendekia.

Sanusi, A. (2015). Sistem Nilai. Bandung: Nuansa Cendekia.
Sugiyono. (2013). Metode Pendidikan Penelitian. Bandung: Alfabeta.

Surahmad, W. (1985). Dasar dan Teknik Research. Bandung: Tarsito.

Suryadi. (2006). Aplikasi Wahyu Illahi dalam Pendidikan. Bandung: Pascasarjana PPS Uninus.

Suryosubroto. (2004). Manajemen Pendidikan di Sekolah. Jakarta. Rineka Cipta.

Tim Dosen. (2013). Manajemen Pendidikan. Bandung: Alfabeta. Undang-undang RI Nomor 20 tahun 2003. Tentang Sistem Pendidikan Nasional. Bandung: Fokusmedia.

Jayadisastra. (2011). pembinaan kepala sekolah.tersedia di http://adesuherman. blogspot.co.id/2011/10 pembinaankepala sekolah.html (20 Maret 2017).

Saodih, S. (2011). Kualitas proses pembelajaran. tersedia di http://sambasalim.com/pendidikan/kualit asprosespembelajan.html oktober2015).

\section{Jurnal}

Rostini. D. (2017 ). Implikasi Kinerja Kepala Sekolah Dalam Manajemen Berbasis Sekolah Di Tingkat Kabupaten Jurnal Bimbingan dan Konseling Ar-Rahman / ISSN 2477-6300 2 (1)

ATR, Rostini. D. (2019 ). Innovation education in the writing of scientific papers social, humanities, and Educational studies (shes): conference series $1(2 \ldots$

Yoseptri R, Rostini. D. (2019). school head management in improving the quality of teacher learning technologi IJIRTE 1 (ISSN), 4

Rostini. D. (2018). Manajemen Penyelenggaraan Pelatihan Kursus 
Tata Rias Wajah untuk masyarakat kabupaten Bandung Barat Kependidikan dan Jawa Barat 9 (issn 2355-4045), 8 